\title{
Experimental investigation on the effect of PCM and nano-enhanced PCM of integrated solar collector performance
}

\author{
C. L. Saw, H. H. Al-Kayiem \& A. L. Owolabi \\ Department of Mechanical Engineering, \\ Universiti Teknologi PETRONAS, Tronoh, Perak, Malaysia
}

\begin{abstract}
The availability of hot water is essential for overnight industrial and domestic use. Integrating the solar heater with thermal energy storage showed a promising result on hot water production when sunlight is not present. In the present work, an outdoor experimental investigation of a flat plate solar collector was carried out with PCM and nano-enhanced PCM. The phase change material (PCM) used in this experiment is paraffin wax. However, $1 \%$ weight fraction of $20 \mathrm{~nm}$ copper nanoparticles was added to improve the properties of the compound. Three cases have been investigated, namely, without PCM, with PCM and with nanoenhanced PCM (nano-PCM). It was found that at the operational mode of $0.5 \mathrm{~kg} / \mathrm{min}$ and at a $10^{\circ}$ inclination angle, with PCM and nano-PCM, hot water at $40.2^{\circ} \mathrm{C}$ and $40.8^{\circ} \mathrm{C}$ was produced the following morning. However, without the PCM case hot water was produced at $35.2^{\circ} \mathrm{C}$. The system was enhanced by $6.9 \%$ and $8.4 \%$ respectively when PCM and nano-PCM were used.
\end{abstract}

Keywords: PCM, solar, nano-enhanced PCM, TES, integrated, nanoparticles.

\section{Introduction}

Domestic water heating, which constitutes a significant share of the residential energy consumption is an excellent application for utilizing solar energy. However, due to the intermittent, unsteady environmental condition and timedependant characteristics of solar radiation, the widespread use of solar water heating systems relies heavily on the availability of reliable and feasible energy storage methods. 
Solar thermal energy has traditionally been stored in the form of sensible heat by raising the temperature of water or rocks for later use [1]. Despite the obvious simplicity of such storage methods, they are inefficient as their storage capacities are small and limited depending on the size of materials. In contrast, solar thermal energy can be stored in the form of latent heat by using suitable phase change materials, which can offer high storage capacity per unit volume and per unit mass [2]. This is essentially due to the fact that for most materials, the latent heat of fusion is very much larger than their enthalpy change (for example, the ratio of latent heat to the specific heat of water is around 80). The melting of phase change material (PCM) enables the absorption of larger amounts of heat which can be excessively available during the daytime. This stored heat can then be released to the surrounding medium during the evening and night hours as the PCM changes its phase again from liquid to solid. Such method of storage is also advantageous in reducing the temperature fluctuations in a solar thermal system by absorbing the extra heat at peak radiation hours and releasing it when solar radiation is absent.

Many researchers try to introduce nanocomposite and nanofluids for the heat storage medium. This is another way to improve the heat storage medium by using nanomaterials [3]. Various nanofluids and nanocomposites have been reported to mainly enhance the thermal conductivity but have not been tested on the solar collector performance. The thermal conductivity of paraffin wax was enhanced by $35 \%$ and $40 \%$ when mixed with multi-walled carbon nanotubes (MWNT), by $1 \%$ and $2 \%$ respectively [4]. The researcher doped $1 \%$ of carbon nanotubes (CNT) into acid based phase change material, the thermal conductivity enhanced by $30 \%$ [5]. Enhancement of $100 \%$ was observed when epoxy was mixed with $1.5 \%$ Carbon Nanotube (CNT) mass fraction [6].

Thus, specific heat capacity $\left(C_{p}\right)$ of materials has shown enhancement by mixing with nanoparticles. Zhou and Ni [7] and Vijjha and Das [8] reported a decrease of $C_{p}$ of aqueous nanofluids. In contrast, the $C_{p}$ of poly-alpha-olefin (PAO) was reported enhanced by $50 \%$ when mixed with $0.6 \%$ of graphite nanoparticles [9]. By using silica nanoparticles, the $\mathrm{C}_{\mathrm{p}}$ of $\mathrm{Li}_{2}-\mathrm{Co}_{3}-\mathrm{K}_{2} \mathrm{CO}_{3}$ eutectic salt was enhanced by $26 \%$ with $1 \%$ mass fraction [10].

Paraffin wax and fatty acids have been used as thermal storage in solar heating and cooling applications but the major drawback is the low thermal conductivity. It leads to a decrease in heat storage during melting and heat retrieval during solidification. Researchers are likely to disperse nanoparticles with high thermal conductivity such as metal nanoparticles, carbon nanofibers or inserted metal matrix into organics PCMs [11]. Carbon nanotubes (CNT) are one of the nanoparticles widely used by researchers to enhance the material's thermal property. An additive of nano powder or nanoparticles is chosen to overcome the low thermal conductivity problem. Hence, 20 nanometer copper powders are dispersed into paraffin wax as this is the smallest size of copper nanoparticles which can be supplied by Hongwu Nanometer Co. 20nm copper powder is chosen as it is very small and has a larger surface area and is higher in thermal conductivity compared to other metals. 


\section{Methodology/experimental set up}

The objective of the present work is to investigate the possibility of enhancing the performance of a flat plate solar collector by using thermal energy storage (TES). Two types of thermal energy storage used are paraffin wax and nanoenhanced paraffin wax. The storage in the present experimental investigation was integrated with a flat plate collector in one single unit (as shown in fig. 1). Nine (9) tubes riser and 37 fins are attached to the absorber plate.

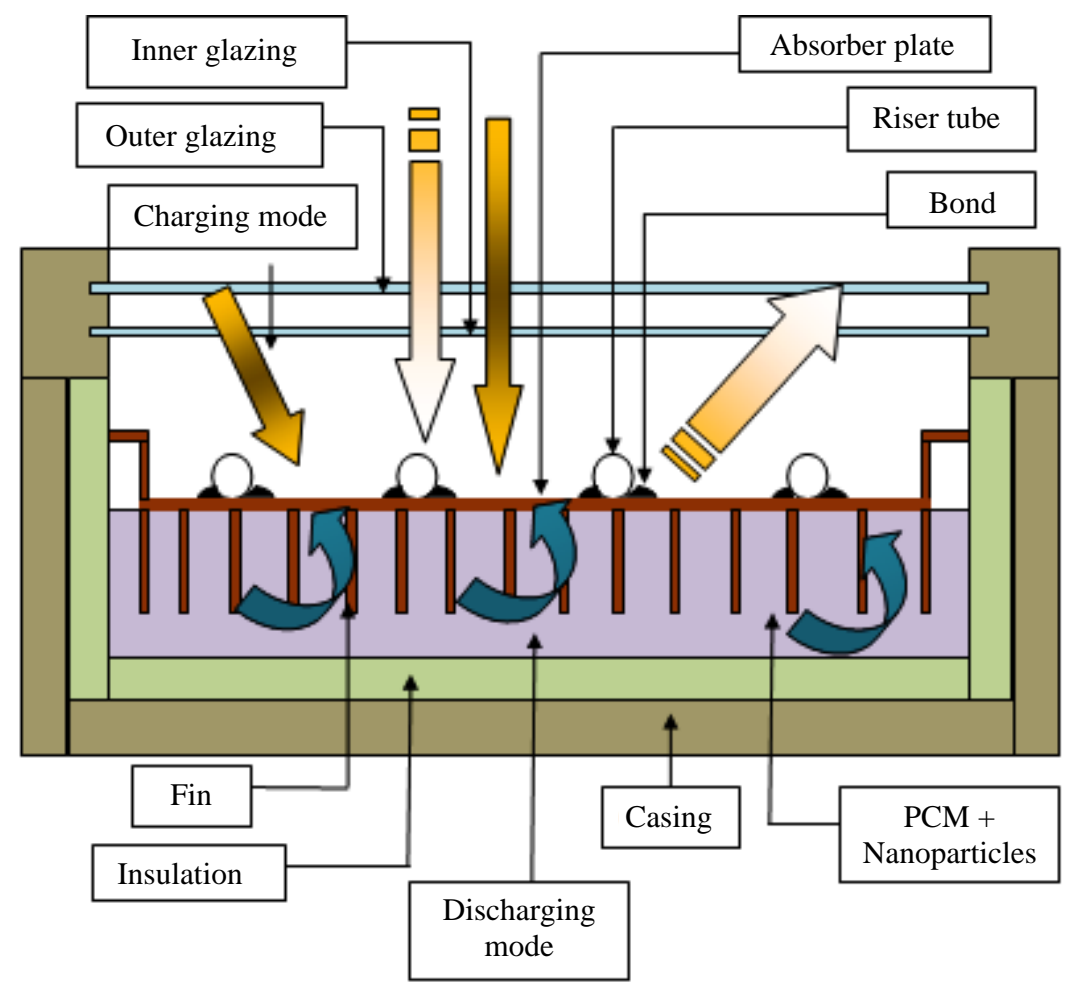

Figure 1: Working principle of charging and discharging of PCM.

The paraffin is in direct contact with the lower surface of the absorber plate, and extended surfaces are introduced to increase the contact area. In the day time, a portion of solar radiation will heat the water in the pipes whereas another portion of solar radiation is used to melt the PCM and nano-PCM TES as a charging process. In the night time, a discharging process will happen. PCM and nano-PCM TES will release heat to heat the water in the pipes. The absorber plate is designed as a heat transfer medium between PCM and water. This system is tested at the inclination angle of $10^{\circ}$ and one flow rate, that is, $0.5 \mathrm{~kg} / \mathrm{min}$. The $10^{\circ}$ inclination can provide optimum solar radiation harvesting as it nears the latitude of the location, while the flow rate is the minimum flow 
rate of the water pump. The system performance is evaluated for a full day cycle (24 hours).

Thermocouple positions at the integrated solar collector are as shown in fig. 2 and fig. 3. 23 thermocouples are attached to the solar collector for measurement. A GRAPHTEC data logger is used to capture the temperature signal for 24 hours with an accuracy of $0.1^{\circ} \mathrm{C} \pm 0.8 \%$. A SHENITEC ultrasonic flow meter is used to measure and control the water flow rate with an accuracy of $0.0001 \mathrm{~m}^{3} / \mathrm{s} \pm$ $0.5 \%$. Solar radiation is captured by using KIMO solarimeter SL200 with an accuracy of $0.01 \mathrm{~W} / \mathrm{m}^{2} \pm 5 \%$.

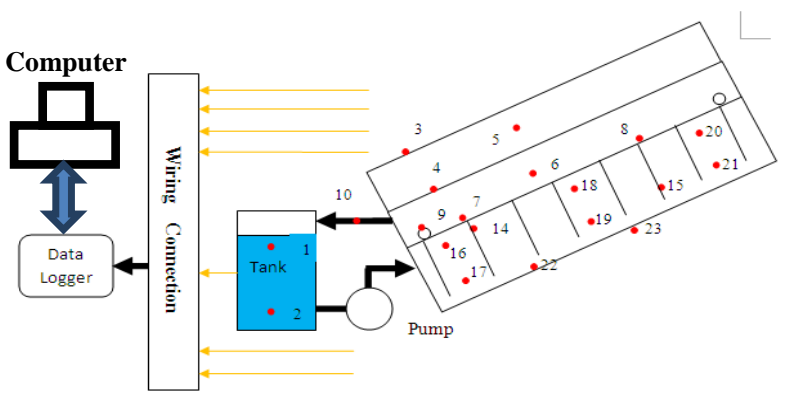

Figure 2: $\quad$ Position of thermocouples in the solar collector.

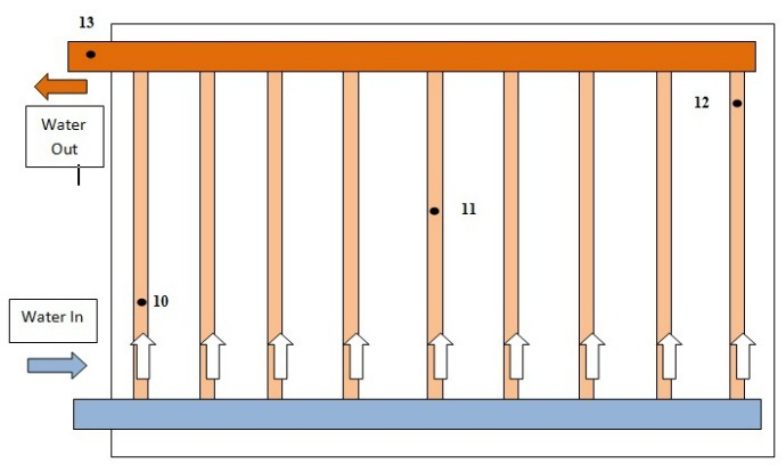

Figure 3: Position of thermocouples in the water pipes.

A $0.5 \mathrm{HP}$ pump is used to circulate water for 15 minutes and stop for 30 minutes before recirculating again for another 15 minutes every hour. A timer is set to switch ON/OFF the pumping operation time for 24 hours. This continuous timing is planned for the absorber plate and paraffin wax to absorb more heat from solar radiation in the day time. This also helps to reduce electricity consumption and provide for a longer life span of the water pump.

At night time, the performance of paraffin wax in the solar collector can be tested during the absence of solar radiation by replacing new fresh water. $28 \mathrm{~kg}$ of paraffin wax is used as thermal energy storage in the PCM case. An additional 
$1 \%$ weight fraction of PCM, that is, $280 \mathrm{~g}$ copper nanoparticles added to PCM for the nano-PCM case. Water is scheduled for withdrawal at 7.00 AM and 7.00 PM every day. All the 60 liters of water is withdrawn and replaced with new fresh water.

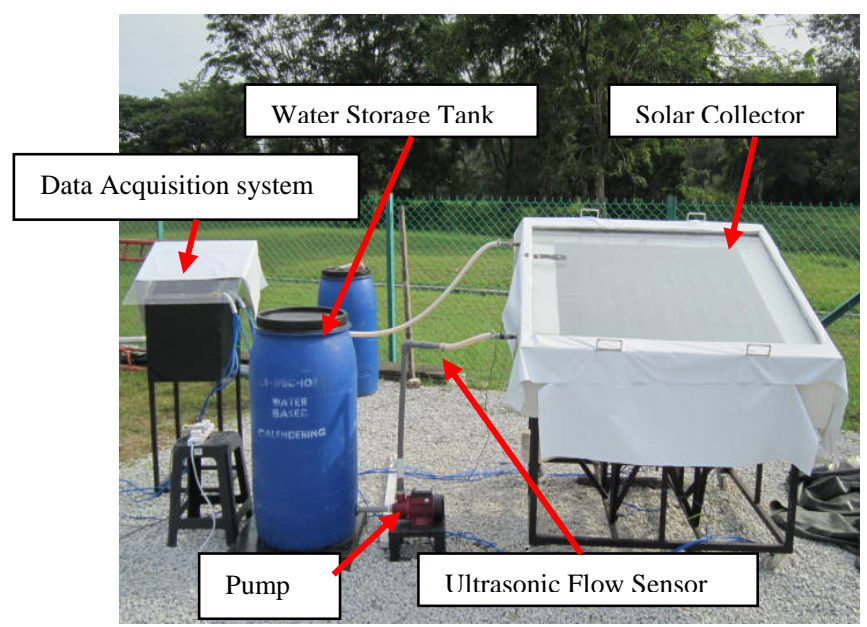

Figure 4: $\quad$ The Integrated Solar-PCM water heater.

The integrated solar collector is placed facing south with a latitude of $4.57^{\circ}$ to capture optimum solar radiation but because of dust and rain water retention, it is advisable to tilt the solar collector $5^{\circ}$ to $10^{\circ}$ higher than its latitude $[12,13]$. In this experiment, 60 liters of water is poured into the tank to be circulated through the solar collector for 24 hours. 60 liters of water is capable of supplying hot water for four (4) persons in a family. The full system consists of one unit 0.5 HP centrifugal pump, 180 liters water tank, solar collector with paraffin wax, a hydraulic jack to set the inclination angle and an ultrasonic flow sensor to measure the inlet flow rate of water into collector shown in fig. 4.

\section{Efficiency evaluation procedures}

The PCM-integrated solar water heater efficiency is predicted from the energy and mass balances involved in the system. The useful energy converted from the solar radiation to useful heating energy is:

$$
\text { Heat Gain, } Q_{u}=\dot{m}_{\text {water }} C_{p \text { water }} \Delta T_{\text {water }}
$$

where $\dot{m}_{\text {water }}=$ Mass flow rate of water $(\mathrm{kg} / \mathrm{s}), C_{p \text { water }}=$ Specific heat of water $\left(\mathrm{J} / \mathrm{kg}^{\circ} \mathrm{C}\right)$ and $\Delta T_{\text {water }}=$ Temperature different of water $\left({ }^{\circ} \mathrm{C}\right), Q_{u}=$ heat gain $(\mathrm{W})$.

The useful heat gain general equation above can be further elaborated into three equations when involving PCM. Since PCM is a phase change material, it consists of sensible heat and latent heat. The equations are as below: 
Heat gain when PCM is in a solid state,

$$
\text { Heat Gain, } Q_{u}=\frac{m_{P C M} C_{p s P C M}\left(T_{S 2}-T_{S 1}\right)}{3600}
$$

where $C_{p s P C M}=$ Specific heat of $\mathrm{PCM}$ during solid phase $\left(\mathrm{J} / \mathrm{kg}^{\circ} \mathrm{C}\right)$ and $T_{S}=$ Temperature at solid state $\left({ }^{\circ} \mathrm{C}\right), m_{P C M}=$ mass of PCM $(\mathrm{kg})$. Heat gain during phase change,

$$
\text { Latent Heat, } Q_{u}=\frac{m_{P C M} C_{p L a t e n t ~ P C M}}{3600}
$$

where $C_{\text {pLatent PCM }}=$ Specific latent heat PCM $(\mathrm{J} / \mathrm{kg})$. Heat gain when PCM is in liquid state,

$$
\text { Heat Gain, } Q_{u}=\frac{m_{P C M} C_{p l P C M}\left(T_{L 2}-T_{L 1}\right)}{3600}
$$

where $C_{p L P C M}=$ Specific latent heat PCM $(\mathrm{J} / \mathrm{kg}), T_{L}=$ Temperature at liquid state $\left({ }^{\circ} \mathrm{C}\right)$.

The solar water heater operation strategy in the experiment is for day and night time. The day time heat source is solar radiation whereas heating for the night time is obtained from PCM. The prediction of the solar collector efficiency is transformed into an equation as follows:

Day and Night time efficiency (without PCM),

$$
\begin{aligned}
& \text { Collector Efficiency, } \eta_{i} \\
& =\frac{Q_{u}}{A_{c} I_{t}} \\
& =\frac{\dot{m}_{\text {water }} C_{p \text { Water }} \Delta T_{\text {Water }}}{A_{c} I_{t}}
\end{aligned}
$$

where $\eta_{\mathrm{i}} \quad=$ Instantaneous Collector Efficiency (\%), $I_{T}=$ Solar radiation $\left(\mathrm{W} / \mathrm{m}^{2}\right), A_{c}=$ Area of solar collector $\left(\mathrm{m}^{2}\right)$ and $\Delta T_{\text {water }}=$ Temperature different water $\left({ }^{\circ} \mathrm{C}\right)$.

The experiment without PCM, with PCM and nano-PCM use the same equation that is equation (5) to predict day time efficiency. The night time efficiency prediction is represented below where the heat gain by water is from discharge of heat by PCM or nano-PCM.

Day and Night time efficiency with PCM,

$$
\begin{aligned}
& \text { Collector Efficiency }, \eta \\
& =\frac{Q_{u}}{A_{c} I_{t}+\frac{m_{P C M} C_{p P C M} \Delta T_{P C M}}{3600}+\frac{m_{P C M} C_{p L a t e n t}}{P C M}}
\end{aligned}
$$

where $\Delta T_{P C M}=$ Temperature difference of PCM $\left({ }^{\circ} \mathrm{C}\right)$ and $C_{P P C M}=$ Specific heat of PCM $\left(\mathrm{J} / \mathrm{kg}^{\circ} \mathrm{C}\right)$. 
Day and Night time efficiency (Nano-PCM),

$$
\begin{aligned}
& \text { Collector Efficiency }, \eta \\
& =\frac{Q_{u}}{A_{c} I_{t}+\frac{m_{\text {NanoPCM }} C_{p N a n o-P C M} \Delta T_{\text {Nano }-P C M}}{3600}+\frac{m_{\text {Nano }-P C M} C_{p L a t e n t ~ N a n o-P C M}}{3600}}
\end{aligned}
$$

where $m_{\text {Nano-PCM }}=$ mass of nanoPCM $(\mathrm{kg}), \mathrm{C}_{\text {plNano-PCM }}=$ Specific heat of nanoPCM during the liquid phase $\left(\mathrm{J} / \mathrm{kg}^{\circ} \mathrm{C}\right), \mathrm{C}_{\text {psNano-PCM }}=$ Specific heat of nano-PCM during the solid phase $\left(\mathrm{J} / \mathrm{kg}^{\circ} \mathrm{C}\right), \mathrm{C}_{\text {LLatent Nano-PCM }}=$ Specific latent heat nano$\operatorname{PCM}(\mathrm{J} / \mathrm{kg})$ and $\Delta T_{\text {Nano-PCM }}=$ Temperature difference of Nano-PCM $\left({ }^{\circ} \mathrm{C}\right)$

Table 1: $\quad$ Thermophysical properties of PCM and Nano-PCM [14].

\begin{tabular}{|c|c|c|}
\hline $\begin{array}{l}\text { Thermophysical Samples } \\
\text { properties }\end{array}$ & PCM & Nano-PCM \\
\hline Melting Point $\left({ }^{\circ} \mathrm{C}\right)$ & 60.5 & 59.6 \\
\hline Solidification Point $\left({ }^{\circ} \mathrm{C}\right)$ & 58.8 & 58.5 \\
\hline Latent Heat, $\mathrm{C}_{\mathrm{pL}}(\mathrm{kJ} / \mathrm{kg})$ & 166.7 & 160.3 \\
\hline Specific Heat, $\mathrm{C}_{\mathrm{ps}}\left(\mathrm{kJ} / \mathrm{kg}^{\circ} \mathrm{C}\right)$ & 1850.0 & 1838.0 \\
\hline Specific Heat, $\mathrm{C}_{\mathrm{pl}}\left(\mathrm{kJ} / \mathrm{kg}^{\circ} \mathrm{C}\right)$ & 2100.0 & 2086.0 \\
\hline Thermal Conductivity $\left(\mathrm{W} / \mathrm{m}^{\circ} \mathrm{C}\right)$ & 0.172 & 0.226 \\
\hline Density, $\rho\left(\mathrm{g} / \mathrm{m}^{3}\right)$ & 908.6 & 976.5 \\
\hline
\end{tabular}

The Perkin Elmer DSC 1 device with an accuracy of $0.01^{\circ} \mathrm{C} \pm 5 \%$ is used to measure the melting point, solidification point, latent heat and specific heat of PCM and nano-PCM. The Ultrapycnometer 1000 device with an accuracy of $0.0001 \mathrm{~kg} / \mathrm{m}^{3} \pm 0.02 \%$ is used to measure the density of the PCM and nano-PCM. A clamp press thermal conductivity device with an accuracy of $0.01 \mathrm{~W} / \mathrm{m}^{\circ} \mathrm{C} \pm$ $0.5 \%$ is used to measure the thermal conductivity of PCM and nano-PCM. The thermophysical properties of PCM and nano-PCM used in this experimental calculation, as shown in Table 1, were adopted from the characterization analysis done on the materials.

\section{Results and discussions}

Five days' set of data for each case has been collected. ASHRAE 93-2003 method [15] is applied for standard measurement and analysis. The collector efficiency combined for the overall daytime and night time without, with PCM and nano-PCM cases are plotted for $0.5 \mathrm{~kg} / \mathrm{min}$ flow rate at a $10^{\circ}$ inclination angle. Uncertainty analysis for the measurement has been calculated by considering random uncertainty and systematic uncertainty as below. As 
calculated, the total uncertainty, $W_{\eta}$ is range $\pm 2.46 \%$ so overall efficiency should include total uncertainty range, where $W_{\eta}, B_{\eta}, P_{\eta}=$ Total uncertainty, Random and Systematic Uncertainty (\%).

$$
W_{\eta}=\sqrt{\left(B_{\eta}\right)^{2}+\left(P_{\eta}\right)^{2}}
$$

The graphs of without, with PCM and nano-PCM collector efficiency are plotted in one graph (as shown in fig. 5). One flow rates and one tilting angle are to test the effects of paraffin liquid's convection on transferring heat to water at night. The enhancement of the thermal conductivity was predicted as:

$$
\text { Percentage of enhancement }=\left[\frac{k_{\text {mixture }}-k_{\text {pure.wax }}}{k_{\text {mixture }}}\right] \times 100
$$

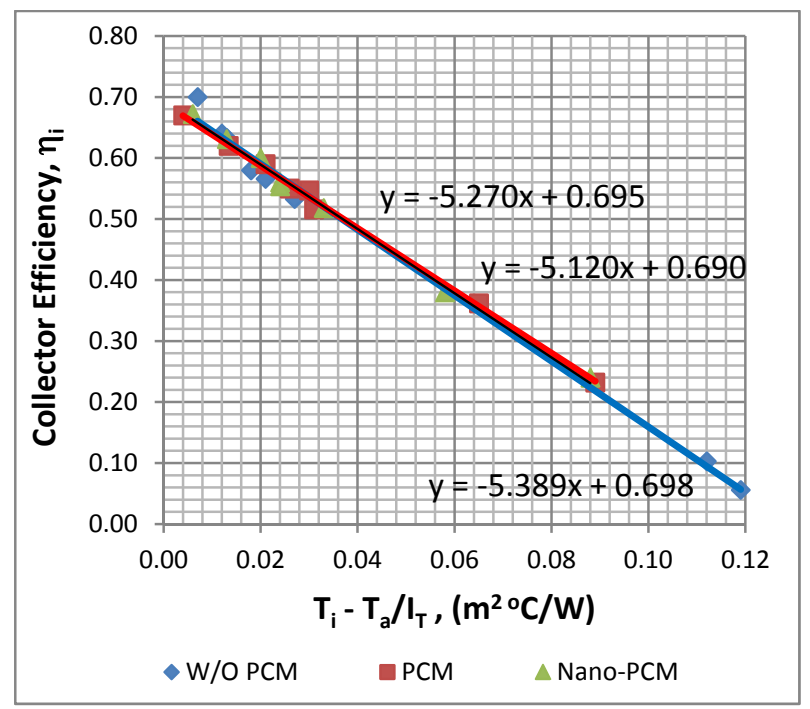

Figure 5: Collector efficiency at $0.5 \mathrm{~kg} / \mathrm{min}$ flow rate and $10^{\circ}$ inclination angle.

The instantaneous efficiency of a solar collector can reach as high as $69.8 \%$ without the PCM case by operating at a $10^{\circ}$ inclination angle and a $0.5 \mathrm{~kg} / \mathrm{min}$ flow rate. Therefore, in the case of PCM and nano-PCM cases, the instantaneous efficiencies were $69.0 \%$ and $69.5 \%$ respectively. This is due to solar radiation captured being utilized to fully heat water in the riser tubes. While, for the case of PCM and nano-PCM, the solar radiation captured was divided to heat the hot water and was absorbed by PCM and nano-PCM TES. The heat loss coefficient, $\mathrm{F}_{\mathrm{R}} \mathrm{U}_{\mathrm{L}}$ is high for the without PCM case. A similar case was found by Saw et al. [16] as the heat loss coefficient $\left(F_{R} U_{L}\right)$ was high for the without PCM case but 
the $F_{R} U_{L}$ was reduced when PCM was used. The researcher also reported that when the inclination increased, the heat loss coefficient factor $\left(\mathbf{F}_{\mathrm{R}} \mathbf{U}_{\mathrm{L}}\right)$ showed an increase in the value whereas the heat absorption coefficient factor $\left(\mathbf{F}_{\mathrm{R}} \tau \alpha\right)$ showed a reduction in value. Hence, the collector efficiency was reduced when the heat loss coefficient factor value was increased and the heat absorption coefficient factor value was decreased.

The inclination angle of $10^{\circ}$ shows an average collector efficiency $47.6 \pm$ $2.46 \%, 51.1 \pm 2.46 \%$ and $51.9 \pm 2.46 \%$ for without, with PCM and nano-PCM respectively (as indicated in Table 2). The PCM and nano-PCM cases have shown an increase in the collector efficiency and have proven to provide good thermal energy storage. With the nano-PCM case, the best enhancement on the collector efficiency was shown but only $1.54 \%$ efficiency improvement when compared with the PCM case. This was due to the non-homogeneity of the mixture of paraffin wax and copper nanoparticles. The non-homogeneous mixture caused a small percentage of suspension of copper nanoparticles on the top of the mixture. On the other hand, the intrinsic behavior of the mixture caused weak bonding between carbon and copper. This shows that the interaction of molecules is weak and reduces the enhancement of the thermophysical properties of the nanocomposite, particularly the thermal conductivity.

Table 2: $\quad$ Integrated Solar-PCM water heater efficiency characteristic for $0.5 \mathrm{~kg} / \mathrm{min}$ flow rate.

\begin{tabular}{|c|c|c|c|c|}
\hline$\theta$ & $\begin{array}{c}\text { Efficiency } \\
\text { Equation }\end{array}$ & $\mathbf{F}_{\mathrm{R}} \tau \boldsymbol{c}$ & $\begin{array}{c}\mathbf{F}_{\mathrm{R}} \mathbf{U}_{\mathbf{L}} \\
\left(\mathbf{W} / \mathbf{m}^{\mathbf{2}} \mathbf{C}\right)\end{array}$ & $\begin{array}{c}\text { Overall } \\
\text { Efficiency }\end{array}$ \\
\hline \multicolumn{5}{|c|}{ Without PCM } \\
\hline $10^{\circ}$ & $\mathrm{y}=0.70-5.39 \mathrm{x}$ & 0.70 & 5.39 & $47.6 \%$ \\
\hline \multicolumn{5}{|c|}{ With PCM } \\
\hline $10^{\circ}$ & $\mathrm{y}=0.69-5.12 \mathrm{x}$ & 0.69 & 5.12 & $51.1 \%$ \\
\hline \multicolumn{5}{|c|}{ Nano-PCM } \\
\hline $10^{\circ}$ & $\mathrm{y}=0.70-5.27 \mathrm{x}$ & 0.70 & 5.27 & $51.9 \%$ \\
\hline
\end{tabular}

In the day time, the collector efficiency of the without PCM case is higher than the with PCM case as all the heat from solar radiation is absorbed by water. However, in at night, the without PCM case efficiency was very low as there is no external heat supply to collector.

The collector efficiency showed an improvement when PCM is used as the thermal energy storage. The collector efficiency was enhanced by $6.9 \%$ and 8.4\% for the PCM case and nano-PCM cases respectively at a $10^{\circ}$ inclination angle.

Overall, the performance of the solar collector showed an enhancement of less than 9\%. The small surface contact between PCM and nano-PCM to absorber plate, low bonding conductivity between riser tubes to absorber plate, low thermal conductivity of PCM, Non-homogeneous of nano-PCM, resistance of the heat transfer rate of absorber plate and heat loss contributed to a low 
percentage of performance enhancement. After the equilibrium, an average of the entire inclination angles, the hot water temperature starts to drop in the range of $1^{\circ} \mathrm{C}-3^{\circ} \mathrm{C}$ until early next morning at 7.00 AM depending on the ambient temperature and environmental conditions, such as rain.

\section{Conclusions}

The optimum operational condition for day time and night time was achieved through a combination of a $10^{\circ}$ inclination angle and $0.5 \mathrm{~kg} / \mathrm{min}$ flow rate. $1.2 \mathrm{~m}$ $\mathrm{x} 1.2 \mathrm{~m}$ solar collector integrated with PCM and nano-PCM were proven to enhance collector efficiency by $6.9 \%$ and $8.4 \%$. The combination also can produce overnight hot water at $40.2^{\circ} \mathrm{C}$ and $40.8^{\circ} \mathrm{C}$. The $0.5 \mathrm{~kg} / \mathrm{min}$ flow rate created a high degree of stratification in the water tank thus improving the collector efficiency.

\section{Acknowledgements}

C. L. Saw expresses his thanks to the Malaysian Ministry of Higher Education for sponsoring the scholarship of $\mathrm{PhD}$ study. In addition, the authors acknowledge Universiti Teknologi PETRONAS for the technical and financial support to conduct the research.

\section{References}

[1] Canbazoglu, S., Sahinaslan, A., Ekmekyapar, A., Akosy, Y.G. and Akarsu, F., Enhancement of solar thermal energy storage performance using sodium thiosulfate pentahydrate of a conventional solar water heating system, Energy Buildings, 37, pp. 235-242, 2005.

[2] Dincer, I., Evaluation and selection of energy storage systems for solar thermal applications, International Journal of Energy Research, 23, pp. 1017-1028, 1999.

[3] Al-Kayiem, H.H., Saw, C.L. and Owolabi, A.F., Review on Nanomaterials for Thermal Energy Storage Technologies, Journal of Nanoscience and Nanotechnologies Asia, 3, 2013.

[4] Wang, J., Xie, H., Xin, Z., Li, Y. and Chen, L., Thermal properties of paraffin based composites containing multi-walled carbon nanotubes, Thermochimica Acta, 488, pp. 39 - 42, 2009.

[5] Wang, J., Xie, H., Xin, Z., Li, Y. and Chen, L., Enhancing thermal conductivity of palmitic acid based phase change materials with carbon nanotubes as fillers, Solar Energy, 84, pp. 339-344, 2010.

[6] Song, Y.S. and Youn, J.R., Influence of Dispersion States Carbon Nanotubes on Physical Properties of Epoxy Nanocomposites, Carbon, 43, pp. 1378-1385, 2005.

[7] Zhou, S. and Ni, R., Measurement of specific heat capacity of water based ALO nanofluid, Appl. Physic. Lett., 92, pp. 0093-123, 2005. 
[8] Vajjha, R.S. and Das, D.K., Specific heat measurement of three nanofluids and development of new correlation, J. Heat Transfer, 131, pp. 71-86, 2009.

[9] Nelson, I.C., Banerjee, D. and Ponnapan, R., Flow loop experiments using polyalphaolefin nanofluids, Journal of Thermophysics and Heat Transfer, 23, pp. 752-761, 2009.

[10] Shin, D. and Banerjee, D., Enhanced specific heat of silica nanofluid, $J$. Heat Transfer, 133, pp. 24-31, 2011.

[11] Sari, A. and Karaipekli, A., Thermal conductivity and latent heat thermal energy storage characteristics of paraffin/expanded graphite composite as phase change material, Applied Thermal Engineering, 27, pp. 1271-1277, 2007.

[12] Kalogirou, S.A., Solar thermal collectors and applications, Progress in Energy Combustion Science, 30, pp. 231-295, 2004.

[13] Henderson, D., Junaidi, H., Grassie, T. and Currie, J., Experimental and CFD investigation of an ICSSWH at various inclination, Renewable and Sustainable Energy Reviews, 11, pp. 1087-1116, 2007.

[14] Saw, C.L. and Al-Kayiem, H.H., Thermophysical Properties of Nano-Phase Change Material Composition for Thermal Energy Storage, Applied Mechanics and Materials, 232, pp. 127-131, 2012.

[15] ASHRAE Standard 93-2003, Methods of testing to determine the thermal performance of solar collectors, Atlanta, GA, USA.

[16] Saw, C.L., Al-Kayiem, H.H. and Aris, M.S., Experimental Investigation on the Performance of Integrated PCM-Flat Plate Solar Collector, Journal of Applied Science, 12 (24), pp. 2390-2396, 2012. 